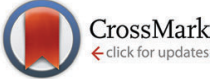

Cite this: Phys. Chem. Chem. Phys., 2016, 18, 29858

Received 23rd September 2016, Accepted 14th October 2016

DOI: $10.1039 / c 6 c p 06533 c$

www.rsc.org/pccp

\title{
Dynamic nitroxyl formation in the ammonia oxidation on platinum via Eley-Rideal reactions $\dagger$
}

\author{
Yunxi Yao and Konstantinos P. Giapis*
}

For over 90 years, nitroxyl ( $\mathrm{HNO}$ ) has been postulated to be an important reaction intermediate in the catalytic oxidation of ammonia to $\mathrm{NO}$ and its by-products $\left(\mathrm{N}_{2}, \mathrm{~N}_{2} \mathrm{O}\right)$, but never proven to form or exist on catalytic surfaces. Here we show evidence from reactive ion beam experiments that $\mathrm{HNO}$ can form directly on the surface of polycrystalline Pt exposed to $\mathrm{NH}_{3}$ via Eley-Rideal abstraction reactions of adsorbed $\mathrm{NH}$ by energetic $\mathrm{O}^{+}$and $\mathrm{O}_{2}^{+}$projectiles. The dynamic formation of $\mathrm{HNO}$ in a single collision followed up by prompt rebound from the surface prevents subsequent reactive interactions with other surface adsorbates and enables its detection. In addition to $\mathrm{HNO}, \mathrm{NO}$ and $\mathrm{OH}$ are also detected as direct products in what constitutes the concurrent abstraction of three surface adsorbates, namely $\mathrm{NH}, \mathrm{N}$, and $\mathrm{H}$, by $\mathrm{O}^{+}$projectiles with entirely predictable kinematics. While its relation to thermal catalysis may be tenuous, dynamic HNO formation could be important on grain surfaces of interstellar or cometary matter under astrophysical conditions.

\section{Introduction}

The catalytic oxidation of ammonia $\left(\mathrm{NH}_{3}\right)$ to nitric oxide (NO) on Pt-Rh gauze (Ostwald process) is one of the oldest industrial reactions still in use today for manufacturing nitric acid. ${ }^{1}$ Surface science techniques and computational approaches over several decades have made great strides towards understanding the ammonia oxidation process. ${ }^{2-7}$ Yet, a broadly accepted molecular-level description of its mechanism is still lacking. It is stunning that three classical ammonia oxidation mechanisms, proposed between 1926-1935, continue to be debated today. Detection of $\mathrm{NH}$ on the Pt surface has favored the imide mechanism of Raschig ${ }^{8}$ and Zawadzki. ${ }^{9}$ The hydroxylamine $\left(\mathrm{NH}_{2} \mathrm{OH}\right)$ mechanism of Bodenstein ${ }^{10}$ and the nitroxyl (HNO) mechanism of Andrussow ${ }^{11}$ have lost appeal, as the postulated surface intermediates remain undetected. ${ }^{6,12,13}$ However, detection may be elusive because the intermediates are extremely short-lived-consistent with the very fast kinetics of the oxidation reaction. Nitroxyl, in particular, has been implicated even in recent times in the formation not only of $\mathrm{NO},{ }^{6}$ but also of the main by-product $\mathrm{N}_{2} \mathrm{O},{ }^{14-16}$ an unregulated but serious atmospheric pollutant. ${ }^{17,18}$ Curiously, nitroxyl has been detected in astrophysical environments (e.g., interstellar clouds), ${ }^{19-21}$ and hydroxylamine has been hypothesized to be a precursor for the formation of complex prebiotic molecules on the surface of interstellar dust grains. ${ }^{22,23}$ Elucidating the surface formation

Division of Chemistry and Chemical Engineering, California Institute of Technology, Pasadena, California 91125, USA. E-mail: giapis@cheme.caltech.edu

$\dagger$ Electronic supplementary information (ESI) available. See DOI: 10.1039/c6cp06533c mechanisms of nitroxyl and hydroxylamine may therefore be important not only for catalysis but also for astrochemistry.

Detection of short-lived reaction intermediates is challenging but critical to revealing the correct elementary steps in heterogeneous catalytic reactions. Both, in situ spectroscopic ${ }^{7,12}$ and beam scattering techniques ${ }^{2-4,24}$ have been applied to the search for reactive intermediates on catalytic surfaces used in the ammonia oxidation process. Beam studies can provide direct mass-spectrometric detection of surface species but they must be performed under collision-free conditions $\left(<10^{-6}\right.$ Torr), necessitating a way to bridge the "pressure gap". Regardless of the technique, the conjectured $\mathrm{HNO}$ or $\mathrm{NH}_{2} \mathrm{OH}$ intermediates have not been detected in spite of extensive efforts. Several other stable species were observed, including: $\mathrm{NH}_{2}, \mathrm{NH}$, $\mathrm{N}, \mathrm{O}, \mathrm{OH}$, and $\mathrm{H}$, providing support for the direct oxidation of $\mathrm{NH}_{3}$ by $\mathrm{O}$ or $\mathrm{O}_{2}$ on the Pt surface. ${ }^{2,3}$ Unless they can be stabilized, transient intermediates produced by forced ejection from the surface must survive the collisional interaction and live long enough to reach the mass spectrometer. The shorter the lifetime, the larger the exit energy required. This prerequisite necessitates the use of projectiles with kinetic energies on the high end of the hyperthermal energy regime (10-100 eV). Collisional interactions at these energies include surface sputtering (i.e., energetic ejection of surface species) but also Eley-Rideal (ER) reactions between projectiles and surface adsorbates. Stable species pre-existing on the surface may be detected intact due to sputtering, or as new molecules when they bond with incident projectiles via Eley-Rideal (ER) reactions. The kinematics of the scattered products can help distinguish unambiguously between these two situations. 
Of course, ER reactions may provide an alternate pathway to the desired intermediate.

\section{Experimental}

The scattering apparatus and associated ion beam-line have been described in detail elsewhere. ${ }^{25-27}$ Isotopically-pure reactive beams of $\mathrm{O}^{+}$and $\mathrm{O}_{2}{ }^{+}$, extracted from an inductively-coupled plasma and mass-filtered, are directed onto a polycrystalline Pt surface (4N purity, ESPI) which is pre-cleaned by sputtering in situ with an $\mathrm{Ar}^{+}$gun. Beam energy is controlled by varying externally the plasma bias with respect to ground. Ion beam currents between 3-5 $\mu \mathrm{A}$ for $\mathrm{O}^{+}$and 8-20 $\mu \mathrm{A}$ for $\mathrm{O}_{2}^{+}$(Fig. S1, ESI $\dagger$ ) are delivered to a grounded surface over a $\sim 3 \mathrm{~mm}$ spot, with tunable energy between 30 and $150 \mathrm{eV}$. Once plasma conditions are selected, the $\mathrm{O}^{+}$beam current is relatively constant over the entire energy range. On the contrary, the $\mathrm{O}_{2}{ }^{+}$beam current varies considerably with beam energy, though it is stable at any given energy. All product intensity data collected are normalized by the corresponding incident current. The energy width of both incident beams is constant at $\sim 5 \mathrm{eV}$ (FWHM), determined by the electron temperature of the inductivelycoupled plasma. The ion beams are delivered to the sample surface at $45^{\circ}$ angle of incidence with respect to the surface normal, and products are detected at $45^{\circ}$ angle of exit. Gaseous ammonia is dosed in situ through a tube ( $2 \mathrm{~cm}$ away), using a leak valve to adjust background system pressure. The exposure pressure at the sample is not measured but it could be an order of magnitude higher than the background pressure due to direct dosing. The energetic $\mathrm{O}^{+}$and $\mathrm{O}_{2}{ }^{+}$projectiles serve as gas-phase reagent and surface probe. They are typically neutralized efficiently on the incoming path and impact the surface as neutral species. ${ }^{28}$ The energetic collision with the metal surface causes hyperthermal surface ionization, ${ }^{29}$ yielding charged products without resorting to electron-impact- or photo-ionization schemes. Finally, the scattered products are energy- and mass-resolved using an electrostatic energy analyzer followed up by a quadrupole mass spectrometer with mass resolution less than $0.5 \mathrm{amu}$ to prevent signal interference between adjacent mass numbers (Fig. S2, ESI $\dagger$ ).

\section{Results and discussion}

Here we perform hyperthermal reactive beam scattering not only to probe surface species but also to study the dynamic formation of intermediates via Eley-Rideal reactions in the ammonia oxidation on polycrystalline $\mathrm{Pt}$ at room temperature under collision-free conditions. In the presence of surface oxygen, $\mathrm{NH}_{3}$ adsorbs dissociatively on the Pt surface to form dehydrogenated ammonia species, which are believed to react directly with surface $\mathrm{O}$ or $\mathrm{O}_{2}$ to form NO. ${ }^{16}$ Our experiment simulates this situation by exposing the Pt surface to thermal $\mathrm{NH}_{3}$ molecules while simultaneously bombarding the surface with $\mathrm{O}^{+}$or $\mathrm{O}_{2}^{+}$projectiles. Partial oxidation intermediates preexisting on the surface may be forcibly ejected by the projectiles (collision-induced desorption). Reactive beam projectiles can also abstract directly surface species in single-collision events, thus forming a new molecule whose detection can uniquely identify the adsorbate. During such scattering experiments, we detected the elusive HNO reaction intermediate, along with other important species.

Since energetic $\mathrm{O}^{+}$projectiles serve both as a probe and a reagent, it is important to first establish how they interact with a clean Pt surface: scattered $\mathrm{O}^{-}$and $\mathrm{O}_{2}^{-}$are produced in this experiment (Fig. 1a and b). At $\mathrm{O}^{+}$incidence energy of $78 \mathrm{eV}$, the scattered $\mathrm{O}^{-}$signal is bimodal with a broad peak at $\sim 25 \mathrm{eV}$ from sputtering of adsorbed $\mathrm{O}$ atoms, and a narrower dynamic peak at $\sim 56 \mathrm{eV}$ from single-bounce scattering off of Pt. Only a single dynamic peak is seen for scattered $\mathrm{O}_{2}{ }^{-}$due to ER reactions between $\mathrm{O}^{+}$projectiles and adsorbed $\mathrm{O}$ atoms. ${ }^{30}$ As soon as the Pt surface is exposed to ammonia at $2 \times 10^{-8}$ Torr, the dynamic $\mathrm{O}^{-}$peak intensity increases by more than $200 \times$ while sputtering contributions diminish (Fig. 1a). The dramatic intensity enhancement is primarily a result of the significant lowering of the Pt surface work function ${ }^{26}$ due to the large dipole moment of ammonia: indeed, the work function of Pt(111) has been shown to decrease by $\sim 3 \mathrm{eV}$ upon ammonia adsorption, albeit at $100 \mathrm{~K}^{31} \mathrm{~A}$ low work function favours negative ion formation during ion-surface charge exchange. ${ }^{26}$ The competition for surface adsorption sites upon $\mathrm{NH}_{3}$ exposure reduces $\mathrm{O}$-atom coverage and suppresses $\mathrm{O}_{2}{ }^{-}$formation. Interestingly, the dynamic $\mathrm{O}_{2}^{-}$peak at an exit energy of $\sim 50 \mathrm{eV}$ virtually disappears upon exposure to $\mathrm{NH}_{3}$, while a slow peak appears at an exit energy of $\sim 10 \mathrm{eV}$ (Fig. 1b). This slow peak cannot be sputtered $\mathrm{O}_{2}$. A possible alternate assignment of mass $32 \mathrm{amu} \mathrm{e}^{-1}$ is hydrazine $\mathrm{N}_{2} \mathrm{H}_{4}$, which however cannot be resolved experimentally from $\mathrm{O}_{2}$. Upon $\mathrm{NH}_{3}$ exposure, $\mathrm{NH}_{2}$ must form on the Pt surface in the presence of oxygen, as reported in the literature. It is conjectured that $\mathrm{NH}_{2}$ can dimerize to form $\mathrm{N}_{2} \mathrm{H}_{4}$, which is sputtered by the $\mathrm{O}^{+}$projectiles to give rise to the observed slow peak at 32 amu in Fig. 1 b.

Continuing onto the observation of reaction products, three new dynamic molecular-ion exits are observed simultaneously: $\mathrm{OH}^{-}, \mathrm{NO}^{-}$and $\mathrm{HNO}^{-}$, shown in Fig. 1c, d and e, respectively. As explained below, these species stem from concurrent direct reactions between $\mathrm{O}^{+}$projectiles and the respective surfaceadsorbed $\mathrm{H}, \mathrm{N}$ and $\mathrm{NH}$ species. In addition, $\mathrm{H}^{-}$and $\mathrm{NH}^{-}$ dynamic peaks are also seen, albeit with much lower exit energies (Fig. 1). Though $\mathrm{NH}_{2}$ is not observed, it cannot be ruled out.

Given the significance of observing a peak at $31 \mathrm{amu}$, some assurance is needed that it is correctly assigned to HNO. First, signal spill over from adjacent peaks at 30 or 32 amu has been discounted by operating the mass spectrometer at very high resolution. Second, contamination from ${ }^{17} \mathrm{ON}$ is not possible given the mass-selected, isotopically pure ${ }^{16} \mathrm{O}^{+}$incident beam and the very minor natural abundance of ${ }^{17} \mathrm{O}$. The only remaining source of contamination may be from ${ }^{15} \mathrm{NO}$, where the ${ }^{15} \mathrm{~N}$ isotope originates in ammonia. The observed peak intensity of mass 31 (" $\mathrm{HNO}^{-, ")}$ is on the order of $4 \%$ of mass 30 ("NO"), at least one order of magnitude larger than the natural abundance of ${ }^{15} \mathrm{~N}$ at $0.37 \%$. Assuming that it is valid to compare the 

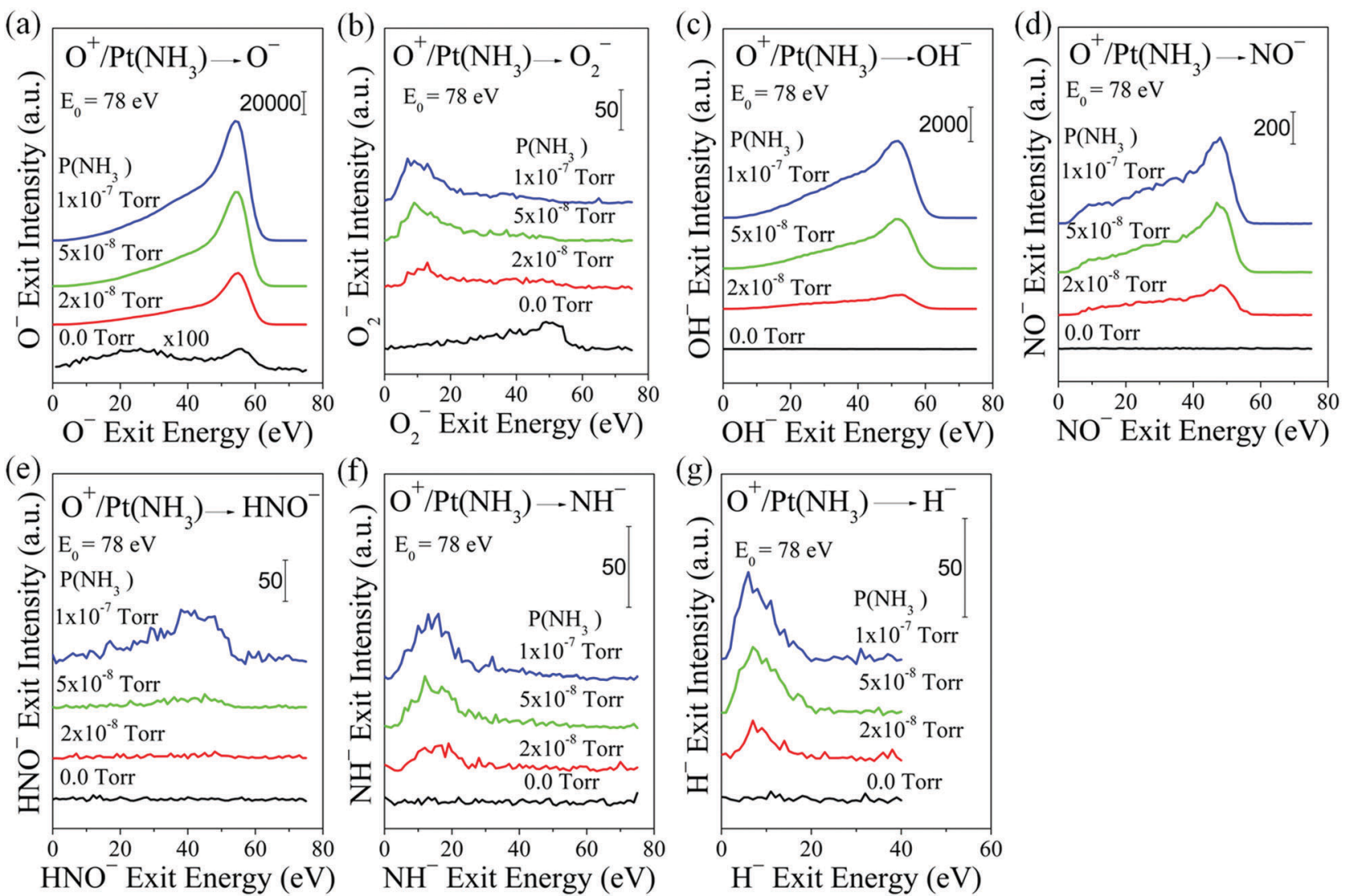

Fig. $1 \mathrm{NH}_{3}$ exposure effect on scattered products. Energy distributions of: (a) $\mathrm{O}^{-}$, (b) $\mathrm{O}_{2}^{-}$, (c) $\mathrm{OH}^{-}$, (d) $\mathrm{NO}^{-}$, (e) $\mathrm{HNO}^{-}$, (f) $\mathrm{NH}^{-}$, and (g) $\mathrm{H}^{-}$from $\mathrm{O}^{+}$bombardment of $\mathrm{Pt}$ at incidence energy of $E_{0}=78 \mathrm{eV}$ and at various $\mathrm{NH}_{3}$ exposure pressures as annotated. The curves at 0.0 Torr represent scattering on a clean Pt surface (in the absence of $\mathrm{NH}_{3}$ ). For all but the $\mathrm{O}_{2}{ }^{-}$product, the scattered peak position remains invariant but signal intensity increases upon ammonia exposure.

intensities of these peaks, this analysis suggests negligible ${ }^{15} \mathrm{NO}$ contribution to the peak at $31 \mathrm{amu}$, thus supporting its assignment to HNO.

The dynamics for the observed scattered products is revealed in Fig. 2, by varying the $\mathrm{O}^{+}$incidence energy; during these experiments, the surface is kept at room temperature while the background pressure of $\mathrm{NH}_{3}$ is raised to $1 \times 10^{-7}$ Torr. The $\mathrm{O}^{-}$, $\mathrm{OH}^{-}, \mathrm{NO}^{-}, \mathrm{HNO}^{-}, \mathrm{NH}^{-}$, and $\mathrm{H}^{-}$ion exit peak positions vary monotonically with $\mathrm{O}^{+}$incidence energy, which suggests that their formation is driven by the $\mathrm{O}^{+}$projectiles. $^{30}$ The low-energy shoulder in the $\mathrm{NO}^{-}$energy spectra is probably due to sputtering of adsorbed NO, formed likely by surface reactions. Close inspection of the $\mathrm{OH}^{-}$and $\mathrm{HNO}^{-}$peaks reveals a low-energy tail-asymmetric peaks.

The observation of $\mathrm{HNO}^{-}$is truly surprising. HNO is highly reactive and thus extremely difficult to detect. In 1926, Andrussow postulated the existence of the nitroxyl (HNO) radical as surface intermediate in the formation of both $\mathrm{NO}$ and $\mathrm{N}_{2}$ during ammonia oxidation. HNO has remained undetected to date in traditional adsorption studies, ${ }^{6,16,32}$ as well as beam studies, ${ }^{2-4,24}$ and this has cast serious doubt to Andrussow's mechanism. Why are we able to finally detect this short-lived intermediate? A notable difference with other beam studies is the use of $\mathrm{O}^{+}$projectiles with hyperthermal energy large enough to
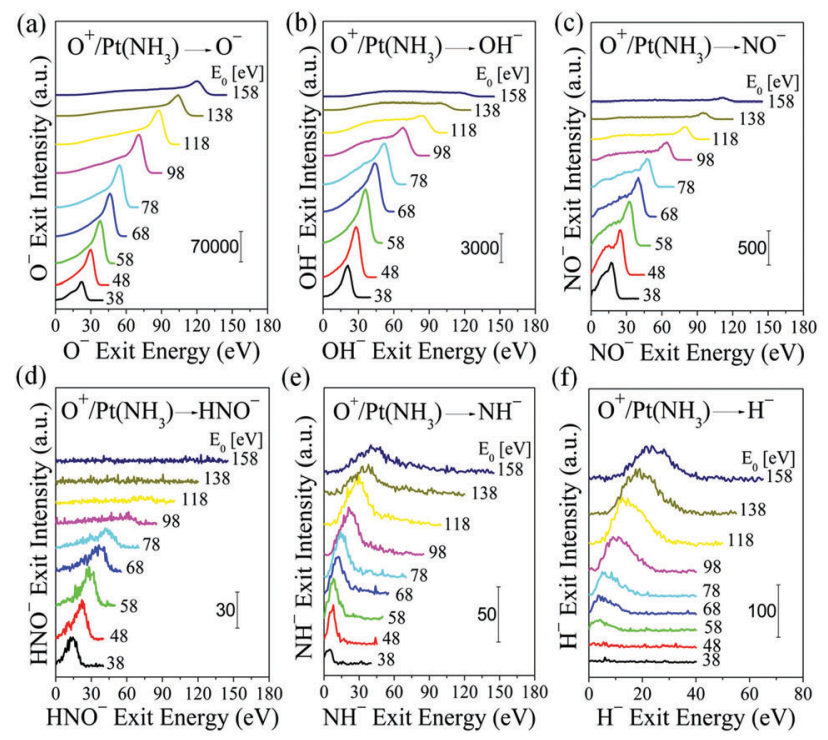

Fig. 2 Energy distributions of scattered products: (a) $\mathrm{O}^{-}$, (b) $\mathrm{OH}^{-}$. (c) $\mathrm{NO}^{-}$, (d) $\mathrm{HNO}^{-}$, (e) $\mathrm{NH}^{-}$and (f) $\mathrm{H}^{-}$from $\mathrm{O}^{+}$bombardment of a polycrystalline Pt surface, held at room temperature and exposed to $\mathrm{NH}_{3}$ at a pressure $1 \times 10^{-7}$ Torr. Results are shown for various $\mathrm{O}^{+}$incidence energies, as annotated. 
allow for: (i) a small distance-of-closest-approach (apsis) to a Pt surface atom so that a transient state can form between the $\mathrm{O}$, $\mathrm{Pt}$, and adsorbed $\mathrm{NH}$, (ii) an extremely short collision time that ejects an energetic $\mathrm{O}-\mathrm{NH}$ before it can react further with other surface species, (iii) HNO formation as anion (with concomitant stabilization) by resonant electron transfer from the Pt surface. ${ }^{26}$ Even with these differentiating advantages, the scattered $\mathrm{HNO}^{-}$ signal is weak versus $\mathrm{OH}^{-}$and $\mathrm{NO}^{-}$ion exits, and it is the first to vanish at $\mathrm{O}^{+}$incidence energies above $100 \mathrm{eV}$.

Kinematic analysis can help pinpoint the origin of these scattering products. The $\mathrm{O}^{-}$signal is produced by single-bounce scattering of incident projectiles, explainable in full by binary collision theory (BCT). ${ }^{33}$ The fast $\mathrm{OH}^{-}, \mathrm{NO}^{-}$and $\mathrm{HNO}^{-}$products can be described by an "atom-in, molecule-out" mechanism, ${ }^{30}$ a true ER abstraction reaction of adsorbed $\mathrm{H}, \mathrm{N}$, and $\mathrm{NH}$, respectively, by $\mathrm{O}^{+}$projectiles, as depicted schematically in Fig. 3a. As such, this is the first case ever shown of three ER reactions taking place concurrently on the same surface. We have described elsewhere ${ }^{30}$ that the ER reaction can be visualized
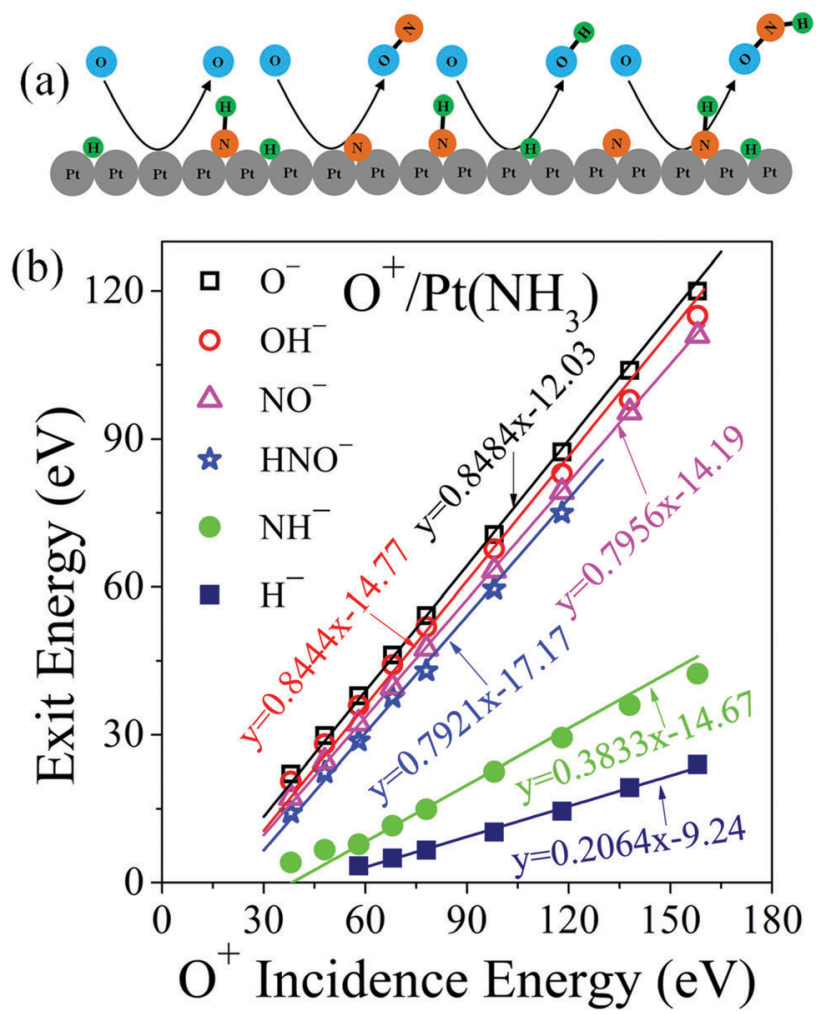

Fig. 3 Eley-Rideal reaction mechanisms and associated kinematics. (a) Schematic depiction of scattering and abstraction reactions occurring between incident $\mathrm{O}^{+}$projectiles and surface adsorbates $(\mathrm{H}, \mathrm{N}, \mathrm{NH})$. (b) Peak ion exit energies of $\mathrm{O}^{-}, \mathrm{OH}^{-}, \mathrm{NO}^{-}, \mathrm{HNO}^{-}, \mathrm{NH}^{-}$and $\mathrm{H}^{-}$as a function of $\mathrm{O}^{+}$incidence energy. The data points represent the energy of the corresponding dynamic peak in Fig. 1. The solid line for $\mathrm{O}^{-}$is a linear fitting with its slope calculated from standard binary collision theory. Solid lines for the direct reaction products $\mathrm{OH}^{-}, \mathrm{NO}^{-}$and $\mathrm{HNO}^{-}$are linear fittings with the slopes predicted from a modified binary collision theory (ref. 30). The $\mathrm{NH}^{-}$data were fitted by assuming $\mathrm{NH}^{-}$forms from dissociation of excited $\mathrm{HNO}$ with a mass-weighted kinematic factor. The $\mathrm{H}^{-}$data were linearly fitted with two parameters. as a three-step process: first, a projectile collides with a substrate atom linked to an adsorbate; second, a triatomic transient state forms at the apsis point between the projectile, the substrate atom and the adsorbate; and third, the transient state disintegrates on the rebound ejecting a projectile-adsorbate molecule from the surface. BCT can predict the kinematic factors of all newly formed molecules. ${ }^{30}$

The exit energy data for $\mathrm{O}^{-}, \mathrm{OH}^{-}, \mathrm{NO}^{-}$and $\mathrm{HNO}^{-}$, plotted in Fig. 3b, exhibit linear dependence on $\mathrm{O}^{+}$incidence energy. The $\mathrm{O}^{-}$exit energy is described very well by a BCT-calculated kinematic factor of 0.8484 , yielding an intercept of $-12.03 \mathrm{eV}$, which corresponds to the inelastic energy loss occurring during the surface scattering process. The calculated kinematic factor for $\mathrm{OH}^{-}$is 0.8444 , which fits the $\mathrm{OH}^{-}$data very well. Given the light mass of $\mathrm{H}$, the kinematic factor of $\mathrm{OH}^{-}$is almost equal to that of $\mathrm{O}^{-}$. The inelastic energy loss for $\mathrm{OH}^{-}$is $14.77 \mathrm{eV}$, which is $2.74 \mathrm{eV}$ larger than the $\mathrm{O}^{-}$exit, probably due to bond rearrangements during its formation (e.g., $\mathrm{Pt}-\mathrm{H}$ ruptures, $\mathrm{O}-\mathrm{H}$ forms). The surface $\mathrm{H}$ atoms, whose presence is confirmed by an $\mathrm{H}^{+}$ sputtering peak (Fig. S3, ESI $\dagger$ ), most likely originate from the dissociation of $\mathrm{NH}_{x}$, though contributions from UHV background hydrogen cannot be excluded. The $\mathrm{NH}^{-}$energy data is dynamic and thus not from sputtering of adsorbed NH. It can be fitted very well by a mass-weighted kinematic factor from dissociating HNO, which suggests that the latter may be formed in an excited state. The $\mathrm{H}^{-}$energy data cannot yet be predicted.

$\mathrm{NO}^{-}$forms by an ER reaction between $\mathrm{O}^{+}$projectiles and adsorbed $\mathrm{N}$ atoms-similar to the reverse process of $\mathrm{N}^{+}$projectiles abstracting adsorbed $\mathrm{O}$ atoms. ${ }^{30}$ The kinematic factor for $\mathrm{NO}^{-}$, calculated to be 0.7956 , describes the $\mathrm{NO}^{-}$exit energy very well. The inelastic energy loss for $\mathrm{NO}^{-}$is $14.19 \mathrm{eV}$, very close to that of $\mathrm{OH}^{-}$, suggesting similarities in scattering. Likewise, the $\mathrm{HNO}^{-}$formation can be described by an ER reaction between $\mathrm{O}^{+}$ projectiles and adsorbed $\mathrm{NH}$ atoms with a kinematic factor of 0.7921. The inelastic energy loss associated with $\mathrm{HNO}^{-}$formation is $17.17 \mathrm{eV}$, about $3 \mathrm{eV}$ larger than $\mathrm{NO}^{-}$formation and comparable to the bond energy of $\mathrm{N}-\mathrm{H}(3.5 \mathrm{eV})$ (32). This difference in energy loss may indicate that there is an $\mathrm{N}-\mathrm{H}$ bond rapture associated with the formation of $\mathrm{HNO}^{-}$, which raises the possibility that this intermediate may be co-produced from $\mathrm{O}^{+}$projectiles abstracting adsorbed $\mathrm{NH}_{2}$ from the surface. ${ }^{5,7}$ Though no $\mathrm{O}-\mathrm{NH}_{2}$ species was detected, we cannot rule out the possibility of its formation as an internally excited intermediate, which subsequently dissociates spontaneously, producing $\mathrm{H}^{+}$and $\mathrm{HNO}^{-}$pair ions. Given the light mass of $\mathrm{H}^{+}$, the kinematics of $\mathrm{HNO}^{-}$produced via this pathway will be indistinguishable from the direct abstraction of $\mathrm{NH}$. This analysis raises the question of whether the observed $\mathrm{NO}^{-}$may likewise be a fragment of $\mathrm{HNO}^{-}$undergoing dehydrogenation. If that were the case, the $\mathrm{NO}^{-}$should exit with slightly lower kinetic energy than $\mathrm{HNO}^{-}$, the opposite of what is observed (Fig. 3b).

Clearly, the observed $\mathrm{HNO}^{-}$forms directly via an ER reaction of energetic $\mathrm{O}$ atoms with adsorbed $\mathrm{NH}$ and, thus, it cannot be considered a surface intermediate. However, its detection is significant as it proves unambiguously that nitroxyl can form in gas-surface collisions and survive long enough to be detected. 
While this method of producing $\mathrm{HNO}^{-}$is dynamic, it is still a surface reaction-albeit with the O-atom at the apsis point closer to the surface rather than at the equilibrium chemisorption position. A conspicuous difference from the Langmuir-Hinshelwood mechanism lies in the fact that the ER reaction produces HNO as anion, which is immediately ejected from the surface, thus preventing subsequent reactive interactions with other surface species. Under industrial catalytic reaction conditions, the adsorbed HNO may be rapidly oxidized to form $\mathrm{NO}$ and $\mathrm{OH}^{6}{ }^{6}$ More importantly, HNO may undergo rapid dehydrative dimerization on the surface, thus explaining the perplexing formation of $\mathrm{N}_{2} \mathrm{O} .^{16,34,35}$

The ER surface reaction process was further tested at elevated surface temperatures. An ordered $(2 \times 2)$ structure of $\mathrm{N}$ atoms has been reported on $\mathrm{Pt}(111)$, formed by annealing a $\mathrm{NH}_{3}-\mathrm{O}$ overlayer to $400 \mathrm{~K}^{36,37}$ Above $400 \mathrm{~K}$, the surface $\mathrm{NH}_{x}$ species are expected to completely dissociate into $\mathrm{N}$ and $\mathrm{H}$. Then, low surface coverage in $\mathrm{NH}$ should suppress the formation of HNO. This prediction was confirmed by performing scattering experiments at elevated temperatures. When raising the temperature from 300 to $420 \mathrm{~K}$, several trends are observed as shown in Fig. 4. First, the $\mathrm{O}^{-}$scattering intensity decreases, which may appear counterintuitive as there should be fewer surface species to react with projectiles, thus allowing more to scatter. Indeed,

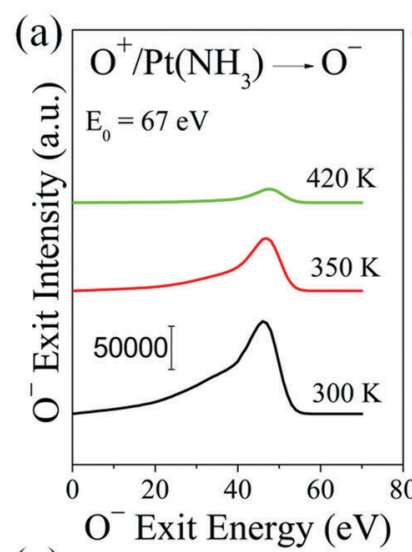

(c)
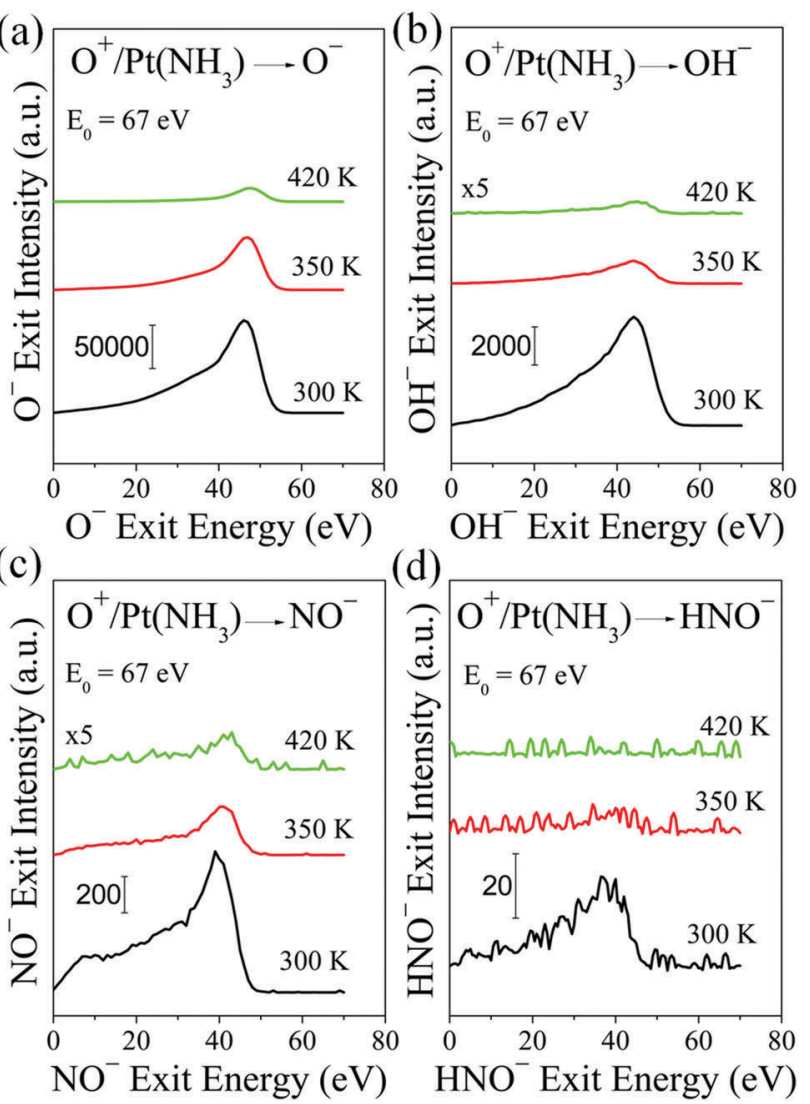

(d)

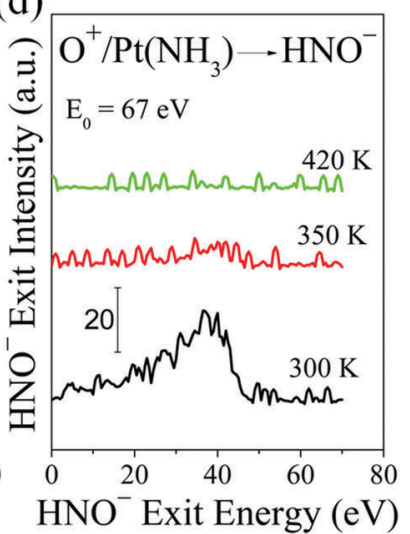

Fig. 4 Surface temperature effect on $\mathrm{NH}_{3}$ adsorbates and scattered product formation. Energy distributions for: (a) $\mathrm{O}^{-}$, (b) $\mathrm{OH}^{-}$, (c) $\mathrm{NO}^{-}$, and (d) $\mathrm{HNO}^{-}$from $\mathrm{O}^{+}$bombardment of Pt at incidence energy of $67 \mathrm{eV}$. The surface is exposed in situ to $1 \times 10^{-7}$ Torr $\mathrm{NH}_{3}$ and its temperature is varied from $300 \mathrm{~K}$ to $420 \mathrm{~K}$. increasing temperature favors desorption and should reduce surface coverage in $\mathrm{NH}_{x}$. However, the reduction in adsorbed $\mathrm{NH}_{x}$ has a significant effect on the Pt surface work function, which influences anion formation disproportionately. Second, the $\mathrm{OH}^{-}$and $\mathrm{NO}^{-}$products exhibit the same trend as $\mathrm{O}^{-}$with a more dramatic reduction in signal intensity. Here the work function effect is compounded by the reduction in surface species ( $\mathrm{H}$ and $\mathrm{N}$ ) needed to react with the incident projectiles. Third, the $\mathrm{HNO}^{-}$signal is barely discernible at $350 \mathrm{~K}$, and disappears entirely above this temperature (Fig. S4, ESI $\dagger$ ). This behavior with temperature agrees with the reported conversion of surface $\mathrm{NH}_{x}$ species to surface $\mathrm{N}$ atoms in the presence of co-adsorbed $\mathrm{O}$ atoms. ${ }^{37}$ Therefore, the observed $\mathrm{NO}^{-}$signal at $420 \mathrm{~K}$ can be attributed solely to the ER reactions between $\mathrm{O}^{+}$projectiles and surface $\mathrm{N}$ atoms. The kinematics of the observed $\mathrm{O}^{-}, \mathrm{OH}^{-}$, and $\mathrm{NO}^{-}$at $420 \mathrm{~K}$ is very similar to room temperature (Fig. S5 and S6, ESI $\dagger$ ).

The final topic of this study pertains to ammonia oxidation with $\mathrm{O}_{2}{ }^{+}$projectiles. The Pt surface is dosed with $\mathrm{NH}_{3}$ as before. Compared to atomic $\mathrm{O}^{+}$, molecular $\mathrm{O}_{2}^{+}$projectiles must undergo collisional dissociation before they can react with adsorbed $\mathrm{NH}_{3}$, probably driven by the high momentum carried by the $\mathrm{O}_{2}{ }^{+}$ projectiles. $^{38} \mathrm{O}_{2}^{+}$scattering on Pt, exposed to $1 \times 10^{-7}$ Torr $\mathrm{NH}_{3}$ at room temperature, yields the following anions: $\mathrm{O}_{2}{ }^{-}, \mathrm{O}^{-}$, $\mathrm{OH}^{-}, \mathrm{HO}_{2}{ }^{-}, \mathrm{NO}^{-}$and $\mathrm{HNO}^{-}$(Fig. 5). The $\mathrm{O}_{2}{ }^{-}$ion exit follows BCT, assuming sequential collisions of the constituent atoms of the molecular projectile. The $\mathrm{O}^{-}$ion exits are produced by collision-induced dissociation, with exit energy roughly about $1 / 2$ of the corresponding $\mathrm{O}_{2}{ }^{-}$ion exits. Surprisingly, there is weak but clear signal corresponding to $\mathrm{HO}_{2}{ }^{-}$, which appears
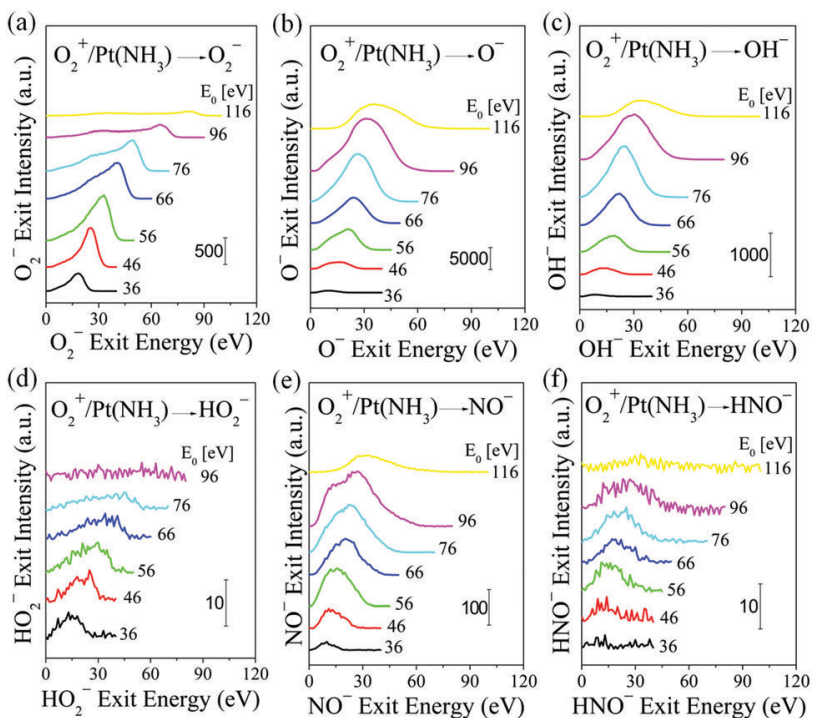

Fig. 5 Ammonia oxidation on Pt by energetic molecular $\mathrm{O}_{2}{ }^{+}$. Energy distributions of scattered products: (a) $\mathrm{O}_{2}^{-}$, (b) $\mathrm{O}^{-}$, (c) $\mathrm{OH}^{-}$, (d) $\mathrm{HO}_{2}^{-}$, (e) $\mathrm{NO}^{-}$and (f) $\mathrm{HNO}^{-}$from $\mathrm{O}_{2}{ }^{+}$bombardment of polycrystalline $\mathrm{Pt}$ at room temperature, exposed to $1 \times 10^{-7}$ Torr $\mathrm{NH}_{3}$ at various $\mathrm{O}_{2}{ }^{+}$incidence energies as annotated. Only $\mathrm{O}_{2}{ }^{-}$and $\mathrm{HO}_{2}{ }^{-}$form in single collisions with predictable kinematics. The ammonia oxidation products $\mathrm{OH}^{-}, \mathrm{NO}^{-}$and $\mathrm{HNO}^{-}$require dissociation of the molecular projectile and, although dynamic, their kinematics cannot be predicted by simple binary collision theory. 
with exit energy almost equal to that of $\mathrm{O}_{2}{ }^{-}$. This suggests that the $\mathrm{HO}_{2}{ }^{-}$is produced by an Eley-Rideal reaction between $\mathrm{O}_{2}{ }^{+}$ projectiles and surface adsorbed $\mathrm{H}$. This direct hydrogenation step may serve to activate the $\mathrm{O}_{2}$ bond under industrial ammonia oxidation conditions, in addition to the catalytic splitting of $\mathrm{O}_{2}$ on Pt. The $\mathrm{HO}_{2}{ }^{-}$peak disappears at $\mathrm{O}_{2}{ }^{+}$incidence energy above $100 \mathrm{eV}$, probably due to dissociation into $\mathrm{OH}^{-}$and $\mathrm{O}$ (or $\mathrm{OH}$ and $\mathrm{O}^{-}$). The fast $\mathrm{OH}^{-}, \mathrm{NO}^{-}$and $\mathrm{HNO}^{-}$products must originate from the direct interaction between $\mathrm{O}_{2}{ }^{+}$projectiles and the respective adsorbed $\mathrm{H}, \mathrm{N}$ and $\mathrm{NH}_{x}$ species, with one fast $\mathrm{O}$ atom from $\mathrm{O}_{2}{ }^{+}$ projectile remaining in the final product. Kinematic plots (Fig. S7, $\mathrm{ESI} \dagger$ ) of $\mathrm{O}_{2}{ }^{-}$and $\mathrm{HO}_{2}{ }^{-}$exit energy data show a linear dependence on $\mathrm{O}_{2}{ }^{+}$incidence energy: both sets are well described by the BCTcalculated kinematic factor of 0.8484 for the $\mathrm{O}_{2}{ }^{-}$exit. The energy loss to form $\mathrm{HO}_{2}{ }^{-}$is $3.8 \mathrm{eV}$ larger as compared to the formation of $\mathrm{O}_{2}{ }^{-}$. For products of $\mathrm{O}_{2}$ dissociation with subsequent surface reaction: $\mathrm{O}^{-}, \mathrm{OH}^{-}, \mathrm{NO}^{-}$and $\mathrm{HNO}^{-}$, the kinematic data cannot be fitted linearly. But for any given $\mathrm{O}_{2}{ }^{+}$incidence energy, the ion exit energies follow a trend similar to that seen in $\mathrm{O}^{+} / \mathrm{Pt}\left(\mathrm{NH}_{3}\right): E\left(\mathrm{O}^{-}\right)>E\left(\mathrm{OH}^{-}\right) \sim E\left(\mathrm{NO}^{-}\right)>E\left(\mathrm{HNO}^{-}\right)$.

\section{Conclusions}

The HNO intermediate has been detected in scattering experiments on Pt surfaces exposed to $\mathrm{NH}_{3}$ under simultaneous bombardment by energetic $\mathrm{O}^{+}$and $\mathrm{O}_{2}{ }^{+}$projectiles. We argue that its direct formation as anion and its prompt ejection from the surface prevents the rapid reaction of HNO with other surface intermediates, enabling its mass-spectrometric detection. Reactive scattering at hyperthermal energies can serve as a method for detecting transient surface intermediates by directly bonding with them via Eley-Rideal reactions.

\section{Acknowledgements}

This report was based on work funded by NSF (Award No. 1202567). We appreciate deeply the thorough reading of the manuscript and the extensive suggestions offered by an anonymous reviewer. It is seldom that someone puts so much effort in a review.

\section{Notes and references}

1 G. B. Taylor, T. H. Chilton and S. L. Handforth, Ind. Eng. Chem., 1931, 23, 860-865.

2 C. W. Nutt and S. Kapur, Nature, 1968, 220, 697-698.

3 C. W. Nutt and S. Kapur, Nature, 1969, 224, 169.

4 M. Asscher, W. L. Guthrie, T. H. Lin and G. A. Somorjai, J. Phys. Chem., 1984, 88, 3233-3238.

5 W. D. Mieher and W. Ho, Surf. Sci., 1995, 322, 151-167.

6 M. Kim, S. J. Pratt and D. A. King, J. Am. Chem. Soc., 2000, 122, 2409-2410.

7 S. Günther, A. Scheibe, H. Bluhm, M. Haevecker, E. Kleimenov, A. Knop-Gericke, R. Schlögl and R. Imbihl, J. Phys. Chem. C, 2008, 112, 15382-15393.
8 F. Raschig, Z. Angew. Chem., 1927, 40, 1183-1185.

9 J. Zawadzki, Discuss. Faraday Soc., 1950, 8, 466-468.

10 M. Bodenstein, Z. Elektrochem., 1935, 41, 466-468.

11 L. Andrussow, Z. Angew. Chem., 1926, 39, 321-332.

12 B. A. Morrow and I. A. Cody, J. Catal., 1976, 45, 151-162.

13 G. Novell-Leruth, J. M. Ricart and J. Pérez-Ramírez, J. Phys. Chem. C, 2008, 112, 13554-13562.

14 J. Pérez-Ramírez, F. Kapteijn, K. Schöffel and J. A. Moulijn, Appl. Catal., B, 2003, 44, 117-151.

15 J. Pérez-Ramírez and E. V. Kondratenko, Chem. Commun., 2004, 376-377.

16 R. Imbihl, A. Scheibe, Y. F. Zeng, S. Günther, R. Kraehnert, V. A. Kondratenko, M. Baerns, W. K. Offermans, A. P. J. Jansen and R. A. van Santen, Phys. Chem. Chem. Phys., 2007, 9, 3522-3540.

17 D. A. Lashof and D. R. Ahuja, Nature, 1990, 344, 529-531.

18 A. R. Ravishankara, J. S. Daniel and R. W. Portmann, Science, 2009, 326, 123-125.

19 L. M. Ziurys, J. M. Hollis and L. E. Snyder, Astrophys. J., 1994, 430, 706-712.

20 T. P. Snow and V. M. Bierbaum, Annu. Rev. Anal. Chem., 2008, 1, 229-259.

21 D. Smith, Chem. Rev., 1992, 92, 1473-1485.

22 J. He, G. Vidali, J. L. Lemaire and R. T. Garrod, Astrophys. J., 2015, 799, 49.

23 G. Fedosseev, S. Ioppolo, T. Lamberts, J. F. Zhen, H. M. Cuppen and H. Linnartz, J. Chem. Phys., 2012, 137, 054714.

24 Y. M. Fogel, B. T. Nadykto, V. F. Rybalko, V. I. Shvachko and I. E. Korobchaskaya, Kinet. Catal., 1964, 5, 496-504.

25 M. J. Gordon and K. P. Giapis, Rev. Sci. Instrum., 2005, 76, 083302.

26 Y. Yao and K. P. Giapis, ChemPhysChem, 2016, 17, 1430-1434.

27 Y. Yao and K. P. Giapis, Angew. Chem., Int. Ed., 2016, 55, 11595-11599.

28 D. Jacobs, Annu. Rev. Phys. Chem., 2002, 53, 379-407.

29 A. Danon and A. Amirav, Int. J. Mass Spectrom. Ion Processes, 1990, 96, 139-167.

30 Y. Yao and K. P. Giapis, Phys. Rev. Lett., 2016, 116, 253202.

31 G. B. Fisher, Chem. Phys. Lett., 1981, 79, 452-458.

32 L. Gang, B. G. Anderson and R. A. van Santen, Appl. Catal., B, 2003, 40, 101-110.

33 D. P. Smith, J. Appl. Phys., 1967, 38, 340-347.

34 J. Pérez-Ramírez, E. V. Kondratenko, V. A. Kondratenko and M. Baerns, J. Catal., 2004, 227, 90-100.

35 J. Schäffer, V. A. Kondratenko, N. Steinfeldt, M. Sebek and E. V. Kondratenko, J. Catal., 2013, 301, 210-216.

36 Z. Liang, H. J. Yang, M. Kim and M. Trenary, J. Chem. Phys., 2014, 140, 114707.

37 Z. Liang, H. J. Yang, J. Oh, J. Jung, Y. Kim and M. Trenary, ACS Nano, 2015, 9, 8303-8311.

38 K. F. Medzihradszky, J. M. Campbell, M. A. Baldwin, A. M. Falick, P. Juhasz, M. L. Vestal and A. L. Burlingame, Anal. Chem., 2000, 72, 552-558. 